\title{
DIREITOS FUNDAMENTAIS COMO RES PUBLICA E COMO FUNDAMENTO PARA A ATUAÇÃO DOS PODERES NO ESTADO DEMOCRÁTICO DE DIREITO*
}

\author{
FUNDAMENTAL RIGHTS AS RES PUBLICA AND GROUND FOR \\ STATE BRANCHES ACTIVITY IN THE DEMOCRATIC STATE OF \\ LAW
}

\author{
MÔNIA CLARISSA"* \\ Rosana HELENA MaAs
}

\begin{abstract}
RESUMO
O presente artigo verifica que repercussões à noção de Constituição e de Direitos Fundamentais como res publica, cunhada por Peter Häberle em estreita conexão com a noção de
\end{abstract}

\begin{abstract}
This article analyses how the notion of Constitution and fundamental rights comprehended as res publica - developed by Peter Häberle in connection with the idea of
\end{abstract}

* Este artigo é resultante das atividades do projeto de pesquisa "Fórmulas de aferição da "margem de apreciação do legislador" (Beurteiligungsspielraum des Gesetzgebers) na conformação de políticas públicas de inclusão social e de proteção de minorias pelo Supremo Tribunal Federal e pela Corte Interamericana de Direitos Humanos", financiado pela FAPERGS (Programa Pesquisador Gaúcho - Edital 02/2017), e pelo Conselho Nacional de Desenvolvimento Científico e Tecnológico - CNPq (Edital Universal - Processo 403533/20180 e Bolsa de Produtividade em Pesquisa Pq - Processo 306417/2018-9). A pesquisa é vinculada ao Grupo de Pesquisa "Jurisdição Constitucional aberta" (CNPq) e desenvolvida junto ao Centro Integrado de Estudos e Pesquisas em Políticas Públicas - CIEPPP e ao Observatório da Jurisdição Constitucional Latino-Americana (ambos financiados pelo FINEP e ligados ao Programa de Pós-Graduação em Direito - Mestrado e Doutorado da Universidade de Santa Cruz do Sul - UNISC). Também se insere no âmbito do projeto de cooperação internacional "Observatório da Jurisdição Constitucional Latino-Americana: recepção da jurisprudência da Corte Interamericana de Direitos Humanos e sua utilização como parâmetro para o controle jurisdicional de Políticas Públicas pelos Tribunais Constitucionais", financiado pela Capes (Edital PGCI 02/2015 - Processo 88881.1375114/2017-1 e Processo 88887.137513/2017-00)

* Com Pós-Doutorado na Ruprecht-Karls Universität Heidelberg (Alemanha) e Doutorado em Direito pela Universidade do Vale do Rio dos Sinos - Unisinos, com pesquisas realizadas junto à Ruprecht-Karls Universität Heidelberg, na Alemanha. Coordenadora e docente permanente do Programa de Pós-Graduação em Direito - Mestrado e Doutorado da Universidade de Santa Cruz do Sul - UNISC, onde ministra as disciplinas de Jurisdição Constitucional e de Controle Jurisdicional de Políticas Públicas, respectivamente. Coordenadora do Grupo de Pesquisa "Jurisdição Constitucional aberta", vinculado ao CNPq. Bolsista de produtividade em pesquisa do CNPq. Membro do Conselho Superior da Fundação de Amparo à Pesquisa do Estado do Rio Grande do Sul - FAPERGS. É autora de livros e artigos publicados no Brasil e no exterior.E-mail: moniah@unisc.br.

** Com Pós-Doutorado na Paris Lodron Universität Salzburg (Áustria) e Doutorado em Direito pela Universidade de Santa Cruz do Sul - UNISC, com pesquisas realizadas junto à Ernst-Moritz-Arndt-Universität Greifswald, Rechts - und Staatswissenschaftliche Fakultät (Alemanha). Professora concursada da Universidade de Santa Cruz do Sul - UNISC, no Curso de Direito e na Pós-Graduação em Direito, onde ministra matérias relacionadas ao Direito Civil, ao Direito Constitucional e à Teoria do Direito. É integrante do grupo de estudos "Jurisdição Constitucional aberta" coordenado pela Profa. Pós-Doutora Mônia Clarissa Hennig Leal, vinculado e financiado pelo CNPq. É autora de livros e artigos publicados no Brasil e no exterior. E-mail: rosanamaas@unisc.br. 
"sociedade aberta de intérpretes da Constituição”, traz para a atuação e a relação entre os Poderes no âmbito do Estado Democrático de Direito, mais precisamente, para os deveres do Estado no sentido de proporcionar espaços democráticos de participação da sociedade, inclusive, quando da efetivação desses direitos. Para dar conta dessa tarefa, utilizar-se-á o método dedutivo e a técnica de pesquisa bibliográfica, notadamente nas obras do publicista alemão Peter Häberle. A teoria do constitucionalista tedesco esteve por muito tempo atrelada apenas à noção de abertura e de participação da sociedade no processo de interpretação da Constituição; aqui, propõe-se uma releitura e atualização dessa teoria, no sentido de aplicá-la também aos demais Poderes Estatais, o que repercute na atuação e na relação entre os mesmos no Estado Democrático de Direito, sendo a eles atribuído o dever de proporcionar espaços democráticos de participação social para a garantia e efetivação dos direitos fundamentais, espaços esses, públicos, abertos, plurais e transparente, não atuando mais a sociedade como mera destinatária dos direitos, mas na construção e legitimação dos mesmos.

PALAVRAS-CHAVE: Constituição. Direitos fundamentais. Res publica. Relação entre Poderes. Peter Häberle.

\begin{abstract}
"open society of constitutional interpreters" - changes the activity and the relation among the State Branches in the ambit of the Democratic State of Law; more specifically, how this impacts the duties of the State in terms of rights implementation. Therefore will be used the deductive method, based on bibliographical research. Häberle's theory is often related to the participation of society in the interpretation of the Constitution; the text intends to widen this conception, extending this perspective to all Branches of Powers, which has repercussions on the performance and the relationship between them in the Democratic State of Law, being assigned the duty to provide spaces democratic spaces of social participation for the guarantee and realization of fundamental rights, public spaces, open, plural and transparent, no longer acting as a mere recipient of rights, but in the construction and legitimation of them.
\end{abstract}

KEYWORDS: Constitution. Fundamental rights. Res publica. Relation among State Branches. Peter Häberle.

\section{INTRODUÇÃO}

Peter Häberle e sua teoria da "sociedade aberta dos intérpretes da Constituição" são temas conhecidos no estudo do direito constitucional brasileiro, principalmente pela contribuição e repercussão de seus escritos na jurisprudência do Supremo Tribunal Federal e na influência que possuiu nas leis do controle concentrado de constitucionalidade e no próprio Código de Processo Civil $^{1}$. Todavia, aqui se pretende discutir a aplicação de sua teoria aos demais Poderes Estatais, o que ecoa na atuação e na relação entre os mesmos. Tratase, mais precisamente, do estudo de um adendo e atualização que o publicista alemão publicou em 1978, ampliando a participação e abertura da sociedade dos intérpretes da Constituição a outros direitos e a diferentes processos.

Nessa perspectiva, a problemática a ser respondida no presente artigo consiste em: que repercussões a noção de Constituição e de Direitos Fundamentais como res publica, cunhada por Peter Häberle em estreita conexão com a noção

1 Nesse sentido, tem-se o instituto do amicus curiae que possui grande notoriedade no processo de controle concentrado de constitucionalidade, sendo inserido no Código de Processo Civil (LEAL; MAAS, 2014). 
de "sociedade aberta de intérpretes da Constituição", traz para a atuação e a relação entre os Poderes no âmbito do Estado Democrático de Direito, mais precisamente, para os deveres do Estado, no sentido de proporcionar espaços democráticos de participação da sociedade, inclusive quando da efetivação desses direitos?

Para responder à presente problemática, utilizar-se-á a metodologia dedutiva e a técnica de pesquisa bibliográfica, primando-se pela leitura nas obras originais do constitucionalista alemão. Desse modo, num primeiro momento, estuda-se a concepção de Constituição e de Direitos Fundamentais como res publica e, em seguida, o adendo e atualização de sua teoria, o que reflete na atuação e relação entre os Poderes no Estado Democrático de Direito, notadamente, no que concerne aos deveres estatais.

A importância do trabalho vem na contribuição para a melhor compreensão e visualização de alguns aspectos controvertidos relacionados ao tema, principalmente, face à leitura atualizada da teoria, tradicionalmente conhecida e atrelada à participação e abertura da interpretação no Poder Judiciário, no processo constitucional, refletindo nos processos de interpretação dos demais Poderes e demais direitos. Buscam-se respostas para novos caminhos e avanços na temática da relação entre os Poderes Estatais e o dever dos mesmos na construção de espaços democráticos e abertos de participação social, bem como de sua responsabilidade na concretização dos direitos fundamentais.

\section{CONSTITUIÇÃO E DIREITOS FUNDAMENTAIS COMO RES PUBLICA: A TEORIA DA "SOCIEDADE ABERTA DOS INTÉR- PRETES DA CONSTITUIÇÃO"}

Peter Häberle realizou seus estudos jurídicos em Tübingen, Bonn e Freiburg. Em 1961, finalizou a sua promoção (Doutorado) junto à Universidade de Freiburg, sendo orientado pelo Professor Konrad Hesse, com o título "Die Wesensgehaltsgarantie des Art.19 Abs. 2 Grundgesetz” (A garantia do núcleo essencial do artigo 19, 2 sobre os direitos fundamentais). Em 1970, concluiu a sua habilitação, também em Freidburg, novamente orientado por Konrad Hesse, sobre o tema "Öffentliches Interesse als juristische Problem" (Interesse público enquanto problema jurídico). Além disso, é interessante destacar que o autor possui influência da Tradicional Escola de Rudolf Smend, de Konrad Hesse e de Horst Ehmke².

Percebem-se, na trajetória de Häberle, dois momentos distintos: o primeiro deles trata da importância da interpretação aberta e cultural da Constituição, advogando por um conceito de Constituição pluralista e democrática, fruto da interpretação da sociedade, não podendo os cidadãos atuarem como meros

2 MORLOK, 2004, p. 328-329. 
destinatários da norma, devendo os mesmos participarem no processo de interpretação constitucional. Em um segundo momento, a partir da década de 90, ganha espaço a ideia de Constituição Cooperativa, cooperação entre Estados, sendo seus textos mais destinados ao direito comunitário Europeu, tendo, inclusive, o autor ganhado prêmio do Instituto-Max-Planck por sua importância referente à Cooperação Internacional ${ }^{3}$. Esclarece-se que o presente artigo pretende dialogar com a primeira fase do autor.

No Brasil, o constitucionalista alemão aufere espaço e conhecimento da comunidade jurídica com a tradução da obra "Die offene Gesellschaft der Verfassungsinterpreten" ("A sociedade aberta dos intérpretes da Constituição"), pelo Ministro Gilmar Ferreira Mendes, em 1997. A sua teoria teve influência na legislação do processo das ações constitucionais do controle concentrado e, principalmente, na instituição do amicus curiae ${ }^{4}$, figura que passa a ter notoriedade, justamente, no processo constitucional, e ganha espaço, hodiernamente, no atual Código de Processo Civil, Lei 13.105/15.

Häberle propõe uma teoria que trabalha com a ideia de uma Constituição aberta, democrática e plural, fruto da interpretação da sociedade, de uma "sociedade aberta dos intérpretes da Constituição" 5_6. Enfim, uma Constituição que é representante do povo $\left(V_{o l k}\right)^{7}$, que a vive e que a legitima ${ }^{8}$. Verifica-se, dessa maneira, que o pressuposto consiste no fato de que a Constituição só será aberta e plural na medida em que a democracia atuar como regente do Estado Constitucional ${ }^{9}$.

3 MORLOK, 2004, p. 328-329.

4 A influência de Peter Häberle na jurisprudência brasileira pode ser notada, por exemplo, na Ação Direta de Inconstitucionalidade 2.469/SC e 3.998/DF (BRASIL, <http://www.stf.jus.br>).

5 No texto Verfassungsinterpretation als öffentlicher Proze $\beta$, de 1978, Peter Häberle (1978c, p.123) refere a influência de Popper em sua teoria, notadamente, na filosofia da "abertura da humanidade" (Offenen Geistes), deixando a Constituição aberta para o futuro, para o desenvolvimento da humanidade e sua história: “Der Philosophie de 'offenen Geistes' gemäß (Popper) läßt die Verfassung Offenheit nach vorn, in die Zukunf, sie institutionalisiert Erfahrungen (Offenheit nach zurück) und läßt Raum für Entwicklungen des menschlichen Geistes und seiner Geschichte”. No entanto, há passagem na mesma obra em que o autor assevera que sua inspiração também foi em Fraenkel, sendo a única encontrada nesse sentido nos trabalhos de Häberle: “[...]v on den angloamerikanischen Verfassungsinstitutionen über Fraenkel und Popper jetz zum Typus des - interpretierten - Grundgesetzes” (HÄBERLE, 1978c, p.145).

6 Esse texto vem a ser publicado em diversos livros do autor, citando-se aqui, como exemplo, "Verfassung als öffentlicher Prozeß: Materialen zu einer Verfassungstheorie der offene Gesellschaft" (1978) e "Die Verfassung des Pluralismus: Studien zur Verfassungstheorie der offenen Gesellschaft” (1980). Ainda, tal texto foi traduzido para o português, já referido acima, como para o espanhol, na obra "Pluralismo y Constitución: estudios de teoría constitucional de la sociedad abierta” (2002), tradução da obra de 1980, aqui mencionada.

$7 \quad$ A ideia de Volk (povo), como Häberle mesmo menciona, não deve ser tomada da mesma forma de Rousseau, na concepção do povo sendo o soberano nacional, mas em um conceito atrelado a um conjunto de cidadãos, em que a democracia corresponde a supremacia dos cidadãos (Herrschaft der Bürger), no sentido que essa democracia é realista: "Die Bürgerdemokratie ist realistische als die Volksdemokratie" (HÄBERLE, 1978d, p. 170).

8 "Volk" ist eben nicht nur einheitliche, (nur) am Wabltag „emanierende" Größe, die als solche demokratische Legitimation vermittelt” (HÄBERLE, 1978d, p. 170)

9 "Im demokratischen Verfassungsstaat ist die Legitimationsfrage noch einmal speziell unter 
O autor busca, assim, uma espécie de "personificação"10 da interpretação constitucional (Personalisierung der Verfassungsinterpretation), sustentando que, por detrás do Estado e de suas funções (Poder Judiciário, intérprete até então único da Constituição), encontram-se pessoas, cidadãos, que, também, devem ser escutados e levados em consideração, quando da interpretação constitucional, no sentido de que são eles os quais vivem essa Constituição (ibrer wesentlichsten Lebens).

Percebe-se que, de tal modo, Häberle"11, através da teoria da "sociedade aberta dos intérpretes da Constituição"12, tece uma crítica aos métodos tradicionais de interpretação, vinculados a um modelo de uma "sociedade fechada" (geschlossene Gesellschaft), reduzindo-se o seu âmbito de investigação, a princípio, à interpretação dos juízes e aos procedimentos formalizados, em que a sociedade não encontra espaço para atuação. Disso decorre que a teoria tradicional de interpretação constitucional preocupa-se, tão-somente, com a tarefa, o sentido (Aufgaben und Zielen) e a metodologia (Methoden) da interpretação constitucional, ou seja, no que se refere ao processo de interpretação e às regras para a mesma, proporcionando apenas uma legitimidade objetiva (Objektivationen der öfentlichen) e formal ${ }^{13}$ da Constituição.

Isso leva o autor ${ }^{14}$ a apresentar uma terceira questão, com relação à participação na interpretação constitucional (Beteiligten der Verfassungsinterpretation), aos sujeitos que realizam essa tarefa constitucional. Nessa perspectiva, Häberle sustenta que "ao lado do questionamento acerca de como e do para que, é preciso que se considere, igualmente, a questão do quem, ou seja, é preciso que esta discussão abarque, também, os participantes (Teilnehmer) da in-

demokratischen (demokratietheoretischen) Gesichts punkten zu stellen" (HÄBERLE, 1978d, p. 169).

10 HÄBERLE, $1978 \mathrm{~d}$, p. 162.

11 HÄBERLE, 1978d, p. 155-181.

12 A tamanha importância que Peter Häberle (1978c, p.123) dá à sua teoria pode ser revelada quando menciona que, assim como os clássicos textos, citando aqui Monstesquieu, Heuss, a teoria que é por ele proposta também deveria constituir o conteúdo pedagógico do Preâmbulo da Constituição: "All dies strukturiert die offene Gesellschaft ebenso wie Klassikertexte (etwa Monstesquieus), Lebensleistungen (etwa T.Heuss'), Präambeln von Verfassungen und ibre pädagogischen Inhalte".

13 Destaca-se que o autor (1978a, p. 28) no artigo ("Demokratische Verfassungstheorie im Lichte des Möglichkeitsdenkes" de 1977, publicado também em obra de 1980) reafirma a sua concepção de que somente através de uma interpretação material da Constituição, pluralista, realizar-se-á uma Constituição Social (aus der Pluralität der Konstitutionellen Gesellschaft), não havendo Constituição sem uma interpretação aberta e plural. Não só isso, em outro trabalho ("Struktur und Funktion der Öffentlichkeit im Democratieschen Staat") Häberle (1980d, p.128) menciona essa importância da alteração de concepção, da necessidade de abertura ao sujeito regido pela norma, vindo a afirmar que, ou a interpretação assume e concretiza essa visão material de interpretação constitucional (Öffentlichkeitsformen) ou terá que se concretizar como um direito ordinário (in der Form der Änderung von Verfassungsoder einfachen Recht).

14 HÄBERLE, 1978c, p. 131. 
terpretação e sua respectiva práxis" ${ }^{15}$. Em razão disso, observa-se que apenas os objetivos e os métodos eram considerados na interpretação constitucional, ficando a reflexão acerca dos sujeitos excluída desse processo.

Daí decorre uma mudança na percepção da teoria da interpretação constitucional, uma oxigenação da mesma, onde a questão acerca de "quem" (wer) interpreta a Constituição ganha espaço: inserem-se, nessa perspectiva, a sociedade e a pluralidade na interpretação constitucional, o que dá um novo sentido a essa mesma interpretação. A nova metodologia proposta é regida pela abertura a novas interpretações ${ }^{16}$, à democracia e à pluralidade.

Nesse contexto, Constituição e realidade influenciam-se reciprocamente, sendo que, ao mesmo tempo em que a Constituição constitui a realidade, ela também é determinada e constituída pela Constituição, questão que o constitucionalista alemão ${ }^{17}$ cita através de uma metáfora, no significado de que a Constituição não seria apenas o espelho da sociedade, mas, também, a sua fonte de luz: "Verfassung ist in diesem Sinne Spiegel der Öffentlichkeit und Wirklichkeit. Sie ist aber nicht nur Spiegel, sie ist auch Lichtquelle, wenn dieser etwas bildhafte Vergleich erlaubt ist. Sie hat Steuerungsfunktion".

Desse modo, o publicista ${ }^{18}$ apresenta a concepção na qual uma interpretação "para e pela sociedade aberta" não pode ficar adstrita aos seus intérpretes oficias, à interpretação dos juízes (Richter); ela deve ser resultado dos interesses da sociedade, dos cidadãos, de grupos e de órgãos oficiais (Poder Legislativo e Executivo), perfazendo-se um processo aberto de interpretação constitucional, não se podendo, nesse processo, limitar os seus participantes, concebendo-se um numerus clausus de intérpretes da Constituição (Es gibt keinen numerus clausus der Verfassungsinterpreten!). Trabalha o constitucionalista, dessa maneira, na perspectiva da inclusão da res publica ${ }^{19}$ à interpretação constitucional, atuando como mudança e consequência para uma interpretação ampla e aberta da Constituição, na ideia de abertura e de pluralidade da mesma.

15 LEAL, 2007, p. 117.

16 O contexto que rege essa temática vem para a concepção da mudança de uma sociedade fechada de interpretação constitucional, para uma teoria que consagra a interpretação constitucional através e para a sociedade aberta da Constituição: "[...] von der geschlossenen Gesellschaft der Verfassungsinterpreten zur Verfassungsinterpretation durch und für die offene Gesellschaft!" (HÄBERLE, 1978d, p. 156)

17 HÄBERLE, $1978 \mathrm{~d}$, p. 156.

18 HÄBERLE, 1978d, p. 156-167.

19 A expressão res publica para identificar a Constituição pode ser encontrada em outros textos do autor, para citar: "Struktur und Funktion der Öffentlichkeit im Democratieschen Staat" de $1980 \mathrm{~d}$ e "Verfassungsinterpretation als öffentlicher Prozeß - ein Pluralismuskonzept" de 1978c; podendo-se conceber essa ideia como resultante da interpretação realizada pela sociedade e para a sociedade (der res publica des Menschen und für den Menschen), assim seja, aberta e plural, chegando o autor a afirmar que concebe essa forma de interpretação como a verdadeira interpretação constitucional (1978a, p. 28). 
Em "sociedade aberta de intérpretes da Constituição", o autor ${ }^{20}$ sugere uma interpretação feita pelo cidadão, sociedade, grupos estatais, não os denominando, o que, em outro artigo ("Struktur und Funktion der Öffentlichkeit im Democratieschen Staat") passa a dar exemplos desses intérpretes, sugerindo a interpretação pelas Igrejas, pela imprensa e por todos que de alguma forma possuem força social. De tal modo, verifica-se que a percepção de participação não vem na ideia de pluralidade geral, mas, de certa forma, de lideranças sociais.

Em continuidade, frente à elaboração dessa concepção, a legitimação, a força (Kraft) da Constituição só ocorre com a inclusão do sujeito, não sendo a Constituição apenas do Estado, em seu sentido estrito (engeren Sinne), mas em um sentido mais amplo (weiteren Sinne), devendo-se compartilhar teoria e prática para a sua realização. Percebe-se, assim, que sua teoria propõe-se a trazer uma percepção mais subjetiva, material ${ }^{21}$ e qualitativa à interpretação constitucional, o que não significa dizer, todavia, que pretende excluir a interpretação dos "intérpretes oficiais"; antes pelo contrário, busca integrá-la à interpretação dos cidadãos, da sociedade, no desenvolvimento da ideia de que a interpretação constitucional vem como tarefa de todos que vivem no contexto regrado pela norma, o que confere um caráter pluralista à mesma ${ }^{22}$.

Em face disso, a elaboração dessa concepção busca romper com a visão de que apenas a interpretação formal da Constituição a legitima, ou seja, a interpretação realizada pelos seus intérpretes oficiais (Vorinterpreten). Advoga o autor ${ }^{23}$ por uma concepção material da interpretação constitucional, por uma interpretação da realidade (Wirklichkeitsdenkes), por um processo constantemente aberto, com o fim de que essa Constituição passe por um processo contínuo de construção, como uma Constituição viva (lebende Verfassung) ${ }^{24}$, obra de todos os seus intérpretes.

A elaboração da presente concepção abre espaço para se abordar também a relação que Häberle ${ }^{25}$ faz entre cultura e direito constitucional (Kulturverfassungsrecht), na qual o elemento cultura passa de um aspecto

20 HÄBERLE, 1980d, p.128-129.

21 Häberle (1978c, p. 131) menciona em outro artigo seu ("Verfassungsinterpretation als öffentlicher Prozeß- ein Pluralismuskonzept”, 1978c), inclusive, que, sem essa perspectiva material da interpretação constitucional, não se teria a Constituição: "Sie ist (vor-läufiges') „Material' für die spätere Verfassungsinterpretation aus der Pluralität der Konstitutionellen "Gesellschaft. Es gibt keine Verfassung ohne pluralistische Öffentlichkeitsinterpretationen und ihre Kontexte".

22 HÄBERLE, $1978 \mathrm{~d}$, p. 156.

23 HÄBERLE, 1978d, p. 156.

24 Viver a Constituição e Constituição viva são expressões correntes nos textos do constitucionalista, por isso, oportuno se faz abordar o conceito do autor de Constituição viva: "Las Constituciones vivas, como obra de todos los intérpretes de la Constitución en una sociedad abierta, son más bien, de acuerdo con su forma y su contenido, expresión y mediación de cultura, marcos para la recepción y (re)producción cultural, así como archivo cultural para las informaciones, las experiencias, las vivencias y el saber popular" (HÄBERLE, 1998a, p. 46).

25 HÄBERLE, 1998b, p. 5 e 27. 
tradicional, de mediação (Kultur is die Vermittlung dessen, was war) para a interpretação constitucional, para um aspecto inovador, de desenvolvimento dessa mesma interpretação (Kultur is die Weiterentwicklung dessen, was war). Nesse olhar, a cultura comporta-se como fator de inovação da Constituição, sendo uma espécie de reflexo da mesma, como resultado entre a simbiose entre a cultura e o direito ("Symbiose" von Recht und Kultur).

A compreensão de "Constituição como cultura"26 (Verfassungskultur) é oriunda da tese da "sociedade aberta de intérpretes da Constituição", sendo do sujeito o papel principal, com suas experiências, atitudes, bem como com seu modo de pensar. A Constituição torna-se fruto da cultura vivenciada pelo povo durante determinado tempo, fruto da sua história, como consequência de sua evolução ${ }^{27}$.

Remetendo-se a outro importante ponto de sua teoria, sendo esse o fator tempo (Zeit und Verfassung), constituindo-se em mais um elemento em face do dualismo cultura e direito, expondo o constitucionalista, inclusive, que a teoria constitucional vive, prima facie, um problema quanto ao tempo ${ }^{28}$.

Dito de outro modo, para o constitucionalista ${ }^{29}$ a interpretação constitucional não é algo que está solto, no vácuo (luftleeren), como algo atemporal (zeitlosen Raum). Concebe-a como resultado de experiências históricas e, também, como forma de transformar essa história, na condição de que somente se pode falar em uma interpretação aberta da Constituição se ela for interpretada em seu tempo e em seu ambiente cultural ${ }^{30}$. A continuidade dessa Constituição só se torna possível, quando passado e futuro estiverem unidos frente à interpretação constitucional ${ }^{31}{ }^{32}$.

26 Assim sendo, com essa teoria, o autor pretende reconstruir a "Constituição" como uma espécie do gênero da "cultura” (SEGADO, 2003, p. XXXVII). Nesse caso específico, cultura teve seu conceito modificado, passando de um conceito restrito para um conceito em um sentido mais amplo, abrangendo, assim, todo o texto legal e toda a ação relevante juridicamente significativa dentro do Estado Constitucional. Ademais, deve-se mencionar que esse conceito é formado por três aspectos: o tradicional, o inovador e o pluralista, dizendo respeito, o primeiro deles, à mediação com aquilo que, em algum momento, existiu; o segundo, por sua vez, ao futuro desenvolvimento em face daquilo que existe; e, o último, ao fato de que um mesmo grupo da sociedade se desenvolve simultaneamente em diferentes culturas (HÄBERLE, 2002b, p. 24-26).

27 “Im Begriff "Verfassung Kultur” als der Summe der subjektiven Einstellungen, Erfahrungen, Werthaltungen, der Erwartungen und des Denke sowie des (objektiven) Handels der Bürger und Pluralgruppen, der Organe auch des Staates etc. [...]” (HÄBERLE, 1998b, p. 91).

28 HÄBERLE, 1998 b, p. 61.

29 HÄBERLE, 1978b, p. 61-64.

30 "Das öffentliche Verständnis der Verfassung ist ein sich in der Zeit bewähren des Verständnis" (HÄBERLE, 1978b, p. 61).

31 O mesmo pode ser observado nos textos da obra: "Verfassungslehre als Kulturwissenschaft", 1998b; como em texto específico do autor: "Zeit und Verfassung”, 1980; e encontra-se trabalho referente à matéria traduzido em espanhol ("Libertad, igualdad, fraternidad. 1789 como historia, actualidad y futuro del Estado constitucional”, 1998a).

32 "Kontinuität der Verfassung ist nur möglich, wenn Vergangenheit und Zukunft in ihr verbunden werden" (HÄBERLE, 1978b, p. 61) 
Percebe-se, nessa perspectiva, que o constitucionalista alemão busca constantemente afirmar, em suas obras ${ }^{33}$, que a sua concepção de interpretação constitucional é uma teoria que se destina para o futuro (Zukunft), fruto da interligação entre tempo e cultura. Apresenta, portanto, a Constituição como um produto cultural, resultante do processo de avanço, inovação e até mesmo de ambição ("Kulturellen Ambicione") da sociedade. Torna-se decorrente das interações e cristalizações (Kulturelle Kristallisationen) daqueles que vivem o contexto regulado por essa norma ${ }^{34}$.

Em face disso, verifica-se que mais elementos são inseridos à teoria do autor, como cultura, tempo e história, todos eles construindo a sua noção de Constituição aberta. É preciso, no entanto, deixar claro que a teoria da "sociedade aberta da interpretação constitucional” aparece com o objetivo para que novos elementos e sujeitos sejam abarcados pela interpretação constitucional, ou seja, não tem a finalidade de excluir os antigos métodos utilizados para ela.

O sentido pretendido é o de relativizar a interpretação jurídica (Relativierung der juristische Verfassungsinterpretation), para que os juízes constitucionais não realizem sozinhos a interpretação constitucional, devendose repartir essa tarefa (am Verfassungsproze $\beta$ Beteilige), na concepção de que apenas com a interpretação de todos os intérpretes da sociedade dar-se-á força normativa à Constituição, em um processo de interpretação público e pluralista $^{35}$. Disso decore, o que de certa maneira já foi frisado, que tão-somente a interpretação aberta e plural, num contexto de cultura, tempo e história de um povo, na ordem democrática, será capaz de efetivar, legitimar a Constituição em seu sentido lato, amplo, e em seu aspecto material e subjetivo ${ }^{36}$.

Nesse teor, os antigos métodos e os princípios da interpretação constitucional não são descartados, mas lhes é atribuída uma nova função, colocando-se os mesmos a atuar como "filtros" (Filter), para o fim de que disciplinem e canalizem as múltiplas formas de influência dos diferentes participantes do processo. Tem-se, dessa concepção, que os antigos métodos de interpretação atuam como limites e como balizadores das distintas formas e sentidos que possa se dar à norma interpretada ${ }^{37}$.

33 A preocupação em afirmar que a sua teoria é uma teoria para o futuro acompanha diversos escritos do autor, podendo-se citar: "Verfassungsinterpretation als öffentlicher Proze $\beta$ - ein Pluralismuskonzept", 1978c; "Demokratische Verfassungstheorie im Lichte des Möglichkeitsdenken”, 1977; "Struktur und Funktion der Öffentlichkeit im Demokratieschen Staat”, 1980d.

34 HÄBERLE, 1998 b, p. 68

35 “Die pluralistische Öffentlichkeit entfaltet normierende Kraft” (HÄBERLE, 1978d, p. 172).

36 "Die im weiteren Sinne Beteiligten und Interpretierenden entfalten eingnständig materielles Verfassungsrecht” (HÄBERLE, 1978d, p. 172-173).

37 HÄBERLE, 1978d, p. 172-173. 
Häberle ${ }^{38}$ designa grande importância a esse aspecto, no sentido de que a sua teoria não exclui as demais, ela propõe uma visão diferenciada, em sentido mais abrangente (weiterem Sinne - cidadãos, grupos, etc.), que acompanhe as outras teorias, advogando que o mais correto é a sua interligação, conjugando a sua interpretação constitucional aberta, democrática e plural, à teoria de interpretação constitucional em sentido estrito (engeren Sinne - métodos e objetos) $)^{39}$. A busca, por conseguinte, não é ocasionar uma revolução à interpretação constitucional, mas a evolução do processo ${ }^{40}$, o que faz com que a nova concepção receba, ao final, um sentido mais profundo ${ }^{41}$.

Percebe-se que publicista ${ }^{42}$ preocupa-se em deixar claro que a sua interpretação constitucional é mais uma das interpretações constitucionais possíveis; não exclui e nem retira a importância de nenhuma outra forma de interpretação. Assim, a regra não é a interpretação aberta e plural, mas, quando da interpretação da Constituição, que essa forma de interpretar seja considerada, que o Povo (Volk) faça parte desse processo ${ }^{43}$.

Frente a essa compreensão, a interpretação da res publica não está à frente da interpretação dos juízes e nem da política, mas é parte dessa interpretação. $\mathrm{O}$ objetivo é que todas as formas de interpretação constitucional sejam aplicadas, compreendendo que a utilização dos tradicionais métodos e princípios pelos juízes constitucionais são necessários, sendo que é através desses que se fará o controle frente a essa atividade, devido às múltiplas influências e às distintas interpretações que poderão surgir. Nesse sentido, o próprio Häberle ${ }^{44}$ lança a preocupação referente a grupos que não possuem interesses organizados (citando as Testemunhas de Jeová, o trabalhador imigrante), não podendo a Constituição se render a eles. Outro aspecto importante diz respeito à intensidade do controle a ser realizado, em que o preceito abordado por Häberle caminha no sentido de que quanto menor (minus) for a participação de diferentes grupos sociais, maior (plus) deve ser o controle da interpretação constitucional ${ }^{45}$.

38 HÄBERLE, 1978c, p. 125 e 129.

39 "Die Verfassungsinterpretation im weiteren Sinne, z. B. die des Verfassungsrichters (und desen Erfahrung), prägt auch deren eigene Verfassungsinterpretation im engeren Sinne mit" (HÄBERLE, 1978c, p. 127).

40 "Es ist im hier verstandenen Sinne nicht revolutionär, sondern evolutinär" (HÄBERLE, 1978a, p. 28).

41 “Die Urteilsformel „Im Name des Volkes” gewinnt dadurch einen tieferen Sinn” (HÄBERLE, 1978c, p. 125).

42 HÄBERLE, 1980d, p. 129.

43 "[...] nicht als Herrschaft,des"Volkes, sondern als Teilhabe, als durch Grundrechtsbestimmungen geschützter und angeregter, durch öffentliche Wablen vollzogener, durch öffentliche kompetenz weitergeführter Vorgang" (HÄBERLE,1980d, p.129).

44 HÄBERLE, 1978c, p. 129

45 HÄBERLE, 1978d, p. 172-173 
Nesse delinear, precisa-se ter presente que não apenas os interesses públicos ${ }^{46}$ serão considerados, mas também os interesses privados que possam vir com esses diferentes grupos, com essas diferentes pessoas; nesse aspecto não só os direitos fundamentais estão presentes na Constituição, deve ela também se preocupar com temas como educação sexual, pré-escola, privacidade, aborto, entre outros, sendo que esses direitos privados também precisam se orientar pela teoria da sociedade aberta, para esses evoluírem, não ficarem no passado ${ }^{47}$, a ponto de o autor ${ }^{48}$ asseverar que a abertura também deve ocorrer nos direitos mais simplórios, ordinários (einfachen Recht), o que demonstra a abrangência de sua teoria ${ }^{49}$.

Em uma palavra: a interpretação constitucional encontra seu significado na abertura, na democracia, no pluralismo, na liberdade e na proteção dos direitos fundamentais, como também no processo constitucional ${ }^{50}$.

Interessante, ainda, mencionar que Häberle ${ }^{51}$ apresenta, nesse contexto, o modelo de "Mesa Redonda" ("runder Tisch"), na ideia de reconstrução do diálogo entre os diferentes atores envolvidos na interpretação constitucional, assim seja, em que juízes e cidadãos, sociedade, organismos estatais e estruturas de dominação totalitária estejam na mesma distância, o que permite que a interpretação constitucional se estabeleça e a ciência da cultura seja ponderada, concebendo-se uma teoria constitucional legítima.

Importante ressaltar, para prosseguir, que o fator democracia torna-se, por conseguinte, o objeto principal, pois somente é possível falar-se em uma interpretação aberta e plural com participação cidadã, através da democracia. Dessa forma, a democracia apresenta-se como meio, ou seja, através dela é possível conceber a abertura e pluralidade como fatores importantes quando da interpretação constitucional, e não como mero resultado. A democracia precisa

46 O constitucionalista preocupa-se em afirmar que a interpretação de grupos e da sociedade não é sinônima de Política, interpretação política, pois, se assim fosse, não seria interpretação da sociedade, mas da política. Nesse contexto, a interpretação política fica a cargo dos Poderes Políticos que também são entendidos como intérpretes da sociedade aberta da Constituição (HÄBERLE, 1998b, p. 123).

47 HÄBERLE, 1978 c, p. 135.

48 HÄBERLE, 1980 d, p. 128.

49 Associado a isso, a Constituição do Estado e da sociedade é concebida em um duplo sentido: a garantia individual de liberdade (Gewährleistung) e o progresso da sociedade (gesellschaftlichen). Ambos os conceitos aparecem ligados à democracia, o que faz reafirmar que a sua teoria está adequada ao âmbito privado e público, na ideia de que o homem não vive na democracia sozinho e a sociedade também não vive sem ela. Além disso, o ponto comum justamente entre esses dois sentidos, resume-se na Constituição da sociedade aberta: "Demokratie und Freiheit haben einen Gemeinsamen Nenner: die Verfassung einer offenen Gesellschaft” (HÄBERLE, 1978e, p. 579-582).

50 "Das Verfassungsverständinis findet seinen Ausdruck in der Akzentuierung von Verfassungsprinzipien wie Öffentlichkeit und Offenheit, Demokratie, Pluralismus, Freiheit, Rechtsschutz, aber auch in bestimmten verfassungsgechtlichen Verfahren (etwas Parlamentsrechts) (HÄBERLE, 1998b, p. 63).

51 HÄBERLE, 1998 b, p. 85. 
ser materializada, porquanto não se contenta com uma perspectiva formal de interpretação constitucional, mas com uma interpretação que una o aspecto formal (visto que o autor não renega os demais métodos, como já asseverado), a política e a prática para a realização dos direitos fundamentais. Nesse contexto, a Constituição deve vir como tarefa de todos, resultante de todas as forças, de uma construção conjunta ${ }^{52}$, e, para legitimar a teoria democrática da interpretação constitucional, o conceito de participação atrelado ao voto e ao poder delegado de decisão não se faz suficiente ${ }^{53}$.

Nessa leitura, a democracia ganha espaço, visto que ela vem determinar o potencial de abertura e de pluralização da interpretação constitucional, ao mesmo tempo em que a abertura e a pluralização vêm determinar a democracia. São elementos que se complementam, que estão ligados, amarrados (verknüpft), pois não há como se falar em abertura e pluralidade em um Estado que não seja Democrático. Essa "reforma" (Reformforderungen) entre abertura e democracia é condizente com o grau de publicidade e de transparência do Estado e da sociedade ${ }^{54}$.

Paralelamente ao todo asseverado, é importante dizer que a teoria de Häberle sofreu várias críticas e oposições, sendo uma delas de autoria de Luhmann, o qual asseverou que a teoria da interpretação constitucional pluralista, aberta, era apenas uma alternativa frente às demais teorias de interpretação constitucional. Em sua defesa, Häberle ${ }^{55}$ afirma que todas as teorias são alternativas, figurando a sua teoria, nesse contexto, como mais uma alternativa diante das diversas alternativas de interpretação constitucional, podendo a sua ser tida como uma alternativa da interpretação da tolerância. Dito de outro modo, é a alternativa para a interpretação constitucional não se fechar (ausschließen) para o futuro.

Não só isso, a tese também foi considerada utópica, incapaz de se realizar, visto que seria muito revolucionária, ao que Häberle ${ }^{56}$ responde no sentido de que a sua teoria vem dar uma perspectiva de salvação para o futuro, para que não caia na presente negligência. Concebe-a como uma alternativa para a proteção das minorias, concretizando os seus direitos, sendo seu objetivo não revolucionar, mas evoluir. Com profundidade, o autor vê essa questão como sendo uma crítica ao racionalismo, à transformação de um pensamento liberal em alternativa de abertura constitucional, realista, ou seja, na sua possibilidade

52 "Ein Verständnis der Verfassung als law in public action ist eben hierdurch mitkonstituiert" (HÄBERLE, 1978e, p. 581).

53 Das allgemeine Bekenntnis zur Demokratie als der ,Staatsform vom Volk gewählter und ihm verantwortlicher Herrschen der genügt" nicht, zumal die nenere sozialwissenschaftliche Demokratie-Diskussion nicht einbezogen ist" (HÄBERLE, 1978e, p. 581).

54 HÄBERLE, 1998b, p. 26.

55 HÄBERLE, 1998b, p. 24.

56 HÄBERLE, 1998b, p. 28-29. 
de pensamento (Möglichkeitsdenken) ${ }^{57}$, dando o exemplo de que, pela garantia dos direitos fundamentais, no domínio econômico, muitas possibilidades de pensamento são institucionalizados, o que também considera utopia.

Corroborando com esse aspecto, menciona-se que o autor, no fim de sua tese, assevera que sua teoria é processual, que sua tarefa consiste numa abertura do processo de interpretação constitucional, um processo de comunicação entre os diversos intérpretes (aller mit allen), para que esse processo político seja tão aberto quanto possível, para que, no seu tortuoso trabalho (abwegige), possua essa alternativa, a alternativa da interpretação aberta e plural ${ }^{58}$.

Nesse caminho, em continuidade, Häberle pretende transpor a sua teoria e alternativa da interpretação aberta e plural aos demais Poderes Estatais, o que repercute na atuação e relação entre os mesmos, mais precisamente quanto aos deveres do Estado no sentido de proporcionar espaços democráticos de participação à sociedade, o que se passa a investigar.

\section{NACHTRAG: A VISÃO ATUALIZADA DA TEORIA COMO FUNDAMENTO PARA A ATUAÇÃO E A RELAÇÃO ENTRE OS PODERES NO ÂMBITO DO ESTADO DEMOCRÁTICO DE DIREITO}

Em 1978, a teoria estudada recebeu um adendo (Nachtrag - comum nos textos do autor), no sentido de que é preciso se ater a um importante questionamento: como uma interpretação com diferentes métodos e sentidos realiza-se frente a diferentes participações? ${ }^{59}{ }^{50}$. Explica-se: Häberle quer chamar a atenção para o fato de que uma interpretação aberta da norma terá dimensões diferentes frente à interpretação do Legislativo, que, por sua vez, possui um processo de interpretação oficial, realizado apenas pelos seus intérpretes oficiais. Dessa forma, a mesma norma será de forma distinta interpretada, o que decorre das diferentes funções e processos de interpretação dos três Poderes do Estado. O objetivo, assim, é pluralizar todos os processos de interpretação, seja do direito constitucional, fundamental ou comum, frente ao Poder Judiciário, Executivo e Legislativo.

57 Sobre a teoria de Häberle ser considerada uma teoria alternativa, compondo as reflexões sobre a possibilidade de seu uso (Möglichkeitsdenkens), o autor dialoga com outras concepções de interpretação constitucional, como reflexões sobre a necessidade (Notwendigkeitsdenkens) e sobre a realidade (Wirklichkeitsdenkens) quando do uso de teorias, tendo-se texto específico do autor em que se discute essas ideias (Demokratische Verfassungstheorie im Lichte des Möglichkeitsdenkes, 1978a e 1980a), afirmando, ao final, que a teoria democrática deve se valer dessas três reflexões (HÄBERLE, 1978b, p. 56-58).

58 HÄBERLE, $1978 \mathrm{~d}$, p. 181.

59 "Unterschiedliche Ziele und Methoden der Auslegung bei verschiedenen Beteiligten?" (HÄBERLE, 1978d, p.177)

60 HÄBERLE, 1978d, p. 177-181. 
Para tanto, o autor ${ }^{61}$ apresenta duas questões importantes, a acima mencionada e àquela que diz respeito quanto à preocupação com a tarefa da teoria de interpretação constitucional (Aufgaben der Verfassungstheorie), em que discute se é possível integrar diferentes formas de interpretação, no caso, do Judiciário e do Parlamento (posteriormente, do Executivo também). A pergunta base a ser respondida corresponde a possibilidade da boa ("guten") interpretação, ou seja, aberta e plural, em sentido amplo, integrar-se a diferentes forças políticas: "Für die Verfassungstheorie stell sich jetzt die Grundfrage, $o b$ es ibre Aufgabe sein kann, die unterschiedlichen politischen Kräfte und d.h. Beteiligten im weitesten Sinne normativ einzubinden, ibren die 'guten' Interpretationsmethoden vorzuschlagen".

Nesse sentido, o constitucionalista advoga que a interpretação constitucional não pode fugir da interpretação realizada pelo legislador, sendo que a interpretação constitucional deve se dar pela (dürch) interpretação do Parlamento, transformando-se uma em espelho da outra (spiegelbildlich).

Busca, desse modo, mostrar a importância da interpretação constitucional feita pelo Legislativo, que também é um dos intérpretes da sociedade aberta da Constituição e, por isso, a sua interpretação deve ser considerada. No entanto, a dimensão é maior, de não somente, como na visão clássica, inserir os demais Poderes na interpretação da Constituição realizada no Poder Judiciário, todavia, de abertura e pluralidade quando da interpretação do direito realizada no processo legislativo e executivo de interpretação da norma.

Destaca-se, portanto, a importância da teoria de Häberle ${ }^{62}$ não estar presente apenas no processo de interpretação constitucional realizada pelo Poder Judiciário, pois esse é compreendido como apenas um dos processos e sistemas de todo um processo maior que pertence à organização e à evolução do Estado. Conforme esse entendimento, o constitucionalista assevera que sua concepção não está presa a uma ordem constitucional, ao direito constitucional, isto é, que essa articulação entre metas, métodos e abertura necessita estar presente também no processo político, no processo legislativo ${ }^{63}{ }^{64}:$ “[...] von politischer Einheit als Ziel verfassungsrechtlicher Verfahren und als Ziel des politischen Prozesses überhaupt ansieht".

A ideia sustentada pelo autor é de que o direito constitucional configura apenas uma das áreas de conflito e de compromisso do Estado (Verfassungsrecht

61 HÄBERLE, $1978 \mathrm{~d}, \mathrm{p} .178$.

62 HÄBERLE, $1978 \mathrm{~d}$, p. 177.

63 Destaca-se que, em primeira análise, Häberle não transporta a teoria ao Poder Executivo o que não representa uma exclusão desse Poder.

64 "Nicht nur für die Verfassungsrechtsprechung und ibre Methoden, sondern auch für eine Verfassungstheorie, die sich mit diesen beschäftigt, ergeben sich aus der Verknüpfung der Fragen nach Ziele, Methoden und Beteiligten der Verfassungsinterpretation neue Fragestellungen" (HÄBERLE, 1978d, p. 177). 
ist nun einmal Konflikt - und Kompromißrecht). O Parlamento também realiza, com seus diferentes interesses e métodos, em face das distintas demandas que lhe são postas, dos mais diversos opositores e partidos, a sua interpretação constitucional ${ }^{65}$.

Nessa linha, em um primeiro momento, o autor apenas expande a sua teoria ao processo político do Poder Legislativo, ou seja, o lócus da teoria ganha espaço maior, sendo tarefa da sociedade e dos cidadãos não só trazer a interpretação pluralística e democrática ao processo constitucional, mas também ao processo legislativo.

Porém, deve-se ter o cuidado para não confundir essa concepção como uma ampliação dos intérpretes judiciais da Constituição, visto que quando o autor fala em todas as funções do Estado, afirma que essas, em seus processos oficiais, devem ser regrados pela abertura da interpretação. A distinção se compõe ao fato de que, a atuação das demais funções do Estado na interpretação constitucional (concepção da teoria da "sociedade aberta dos intérpretes da Constituição”), já é pressuposto da teoria, o que objetiva com o Nachtrag é inserir essa concepção, como teoria do direito, a outras áreas do direito, aos processos das demais funções do Estado, Poder Executivo e Legislativo.

Nota-sequea teoria “Dieoffene GesellschaftderVerfassungsinterpretation" é de 1975, havendo recebido o mencionado adendo em 1978, como já referido. No entanto, em 1980, foi publicado o Livro "Die Verfassung des Pluralismus: Studien zur Verfassungstheorie der offenen Gesellschaft" (A Constituição do Pluralismo: estudos sobre a teoria constitucional da sociedade aberta), em que, no texto "Struktur und Funktion der Öffentlichkeit im demokratischen Staat" (Estrutura e função pública no Estado Democrático), o autor amplia ainda mais à sua teoria democrática e pluralista, estendendo-a a todos os Poderes Estatais ${ }^{66}$. Verifica-se que, num primeiro momento, a ampliação, deu-se apenas ao Poder Legislativo.

Häberle ${ }^{67}$ fundamenta tal concepção, a princípio, no aspecto de que toda autoridade do Estado vem do Povo (alle Staatsgewalt geht vom Volks aus), o que, de certa forma, consiste no fundamento de sua teoria, isso para concluir que todas as estruturas estatais são justificadas pela abertura da interpretação, legitimando-se através de uma interpretação aberta e plural.

$\mathrm{O}$ principal argumento do autor ${ }^{68}$ encontra-se na afirmação de que o princípio da abertura da interpretação, no sentido de uma interpretação pública

65 HÄBERLE, 1978d, p. 177.

66 HÄBERLE, 1980d, p. 126-162.

67 HÄBERLE, 1980d, p. 129.

68 "Sie ist Rechtsprinzip (nicht nur politisches Formprinzip) mit sehr konkreten Folgerungen bis in juristische Auslegungsfragen im einzelnen binein - sofern man in spezifisch verfassungsrechtlichen, durchaus juristischen Ansatz und nicht auf dem Boden eines engen Interpretationsverständnisses argumentiert" (HÄBERLE,1980d, p. 130). 
e plural, é um princípio do direito (Rechtsprinzip), um princípio democrático que é aplicado à interpretação da Constituição, mas não pertence somente a ela, não devendo ficar restrito a esse lócus de atuação. Dessa forma, tal princípio é atribuído não apenas ao direito constitucional, mas a todo o ordenamento jurídico ${ }^{69}$. O que faz a abertura através da participação tornar-se princípio legitimador da res publica ${ }^{70}$.

Nesse sentido, o Poder Judiciário apresenta-se como clássica função aberta do Estado, visto que não há justiça privada (Es gibt keine private Gerechtigkeit), os juízes são juízes públicos e desejam uma justiça pública, isso num contexto em que conhecimento e interesse (concepção que o autor utiliza de Habermas: "Erkenntnis und Interesse) nos casos judiciais aparecem interligados à ideia de transparência dessa atividade. A abertura do processo no Poder Judiciário vem, dessa forma, como uma "antiga exigência democrática" ( "alte demokratische Forderung ") e se constitui fundamental na instituição do Estado de Direito ${ }^{71}$.

Já o Poder Executivo tem a sua concepção original não atrelada à publicidade, não constitui uma função aberta por excelência (nichtöffentlichen Funktion). O Poder Executivo, com sua tradição monárquica, aparece como um Poder que possui uma "negativa relação" com a abertura para a democracia, como uma função social não aberta, não pública ${ }^{72}$. Desse modo, destaca-se a necessidade de a abertura não figurar apenas como uma alternativa a ser ponderada pelo Poder Executivo, mas como uma obrigação que lhe é imposta; e, aqui, verifica-se que o fator publicidade se apresenta como um fator importante na mudança de concepção do Poder Executivo ${ }^{73}$.

Nesse quadro, o que o autor objetiva é ampliar a sua teoria aos Poderes Estatais, vindo a concebê-los, no processo democrático da res publica, como funções abertas, correspondentes a um processo aberto e democrático de decisão. Daí que, para haver a legitimação desses Poderes e o controle dos mesmos, peça

69 "Demokratische Öffentlichkeit ist normative Öffentlichkeit mit dem Anspruch eines Wertbegriffs, und insofern wirkt sie legitimierend für die öffentlichen Gesamtordnung" (HÄBERLE, 1980d, p.130).

70 "Über 'öffentliche vollzieht sich Teilhabe an den Legitimacionsprinzipien' des res publica" (HÄBERLE, 1980d, p.130).

71 Note-se que Häberle (1980d, p. 136) menciona que a democracia e o Estado de Direito exigem proporcionalmente a abertura do Poder Judiciário, sendo que, em sua concepção liberal, tais fatores vinham interligados com a ideia de publicidade desses atos: "Demokratie und Rechtsstaat fordern gleichermaßen die Öffentlichkeit der richterlichen Funktion, und das frübliberale Schrifttum hat mit Grund auf diesen Publizitätsforderungen Beständen".

72 "Die Executive steht infolge ihrer monarchischen Arkantradition in weiten Bereichen (z. B. auch in dem derb Ermessensverwaltung und der Regierung) in einen ,Negativverhältnis" zur demokratischen Öffentlichkeit. Gerade hier war öffentlich identisch mit staatlich. Von primär öffentlicher Funktion zu sprechen fällt besonders schwer. Entsprechend eng ist die Affinität zu einen ,staatlichen" (nichtöffentlichen) Gemeinwohlsvertändnis. Zumal die Geheimhaltungsgemeinwohltatbestände, derem Adessat die Executive ist, belassen dieses nichtöffentliche Funktion" (HÄBERLE, 1980d, p. 135).

73 HÄBERLE, 1980d, p. 135. 
fundamental se torna a publicidade de suas ações, de uma grande transparência delas, partindo-se do entendimento de que os assuntos públicos devem ser, por regra, transparentes ${ }^{74}$.

A abertura e a democracia aparecem interligadas, dessa maneira, ao conceito de publicidade e de transparência das ações, como sendo condições necessárias para que a interpretação aberta e plural possa se concretizar. A abertura das funções estatais, no Estado Social e na República, exige a publicidade dos acontecimentos estatais ${ }^{75}$. Percebe-se, assim, que o Estado e seus entes possuem o dever de tornarem públicas e transparentes as suas funções, atos, decisões e interpretações, não só do texto constitucional, mas de todas as suas tarefas, ações delegadas aos Poderes pelo povo.

A democracia, no Estado Social e na República, apresenta-se como uma delegação de responsabilidade frente ao povo. Nesse diapasão, através da abertura dos Poderes estatais é que se torna possível a abertura para o controle, o que só ocorre quando se tem a publicidade como fundamento da democracia ${ }^{76}$, o que permite concluir que a sociedade precisa ter acesso aos assuntos públicos e possuir suporte para acompanhá-los e controlá-los, devendo o Estado fornecer meios para que isso ocorra. No Brasil, observa-se o amicus curiae, as audiências públicas (em todos os Poderes Estatais), as comissões parlamentares, os conselhos municipais, os Portais de Transparência e e-Sic (visto que sem informação e transparência, não há participação legítima).

Com esse objetivo, a abertura, a legitimidade e o controle das ações estatais vêm a ser determinadas pela forma com que a democracia se apresenta, por quão pública e transparente ela se $\operatorname{mostra}^{77}$; em compreensão de que a exigibilidade por publicidade aparece como a exigibilidade por democracia ${ }^{78}{ }_{-}^{79}$.

Disso decorre que a teoria de Häberle deixa claro que configura dever do Estado e dos seus entes estatais proporcionar a abertura de suas estruturas para a interpretação e atuação da sociedade, dos cidadãos, em um contexto marcado pela abertura da interpretação nos diferentes órgãos estatais. Abertura e democracia aparecem, assim, como conceitos que se formam e se concretizam juntamente. A abertura aos setores sociais, na interpretação constitucional, na interpretação de atos dos demais Poderes Estatais, torna-se princípio

\footnotetext{
74 "Die öffentlichen Angelegenheiten, um derentwillen Herrschaft ausgeübt werden soll, müssen transparent (öffentlich) sein” (HÄBERLE, 1980d, p. 130).

75 HÄBERLE, 1980d, p. 130.

76 HÄBERLE, 1980d, p. 135-136.

77 "Vor allem bestimmte staatsrechtliche Reformforderungen stehe im Zeichen von Demokratie und Öffentlickeit (größere Transparenz von Staat und Gesellschaft)” (HÄBERLE, 1980d, p. 126).

78 "Die oft geforderten Publizitätsgesetze sind insofern „Demokratiesgesetz" (HÄBERLE, 1980d, p. 126).

79 HÄBERLE, 1980d, p. 126
} 
fundamental do Estado do Direito, princípio fundamental para todas as áreas públicas do Estado.

\section{CONCLUSÃO}

Peter Häberle, ao apresentar o adendo e a atualização da teoria da “sociedade aberta dos intérpretes da Constituição”, propõe uma personificação da interpretação em todos os processos de interpretação dos Poderes Estatais. Uma interpretação caracterizada pela abertura e pela pluralidade, na qual fatores como cultura, tempo e história são predominantes. $\mathrm{O}$ autor quer chamar a atenção para o fato de que uma interpretação aberta da norma terá dimensões diferentes frente à interpretação do Legislativo e do Executivo, que, por sua vez, possuem um processo de interpretação oficial. Por esse motivo, propõe que a "interpretação aberta" seja aplicada a todos os Poderes Estatais em sua atividade de intepretação do direito constitucional e de concretização dos direitos fundamentais.

Desse modo, a atualização de sua teoria ocorre em dois sentidos: 1) abertura e pluralidade nos Poderes Executivo e Legislativo quando da interpretação do direito constitucional e do direito fundamental; 2) abertura e pluralidade em todos os Poderes quando da interpretação de qualquer direito ordinário, comum. Apresentam-se, pois, duas ampliações à teoria.

Essa abertura e pluralidade se dá, por sua vez, através de espaços democráticos voltados a esse fim, regidos pela publicidade e pela transparência, sendo dever dos Poderes Estatais construir esses espaços de participação social. Citam-se como exemplo, nesse sentido, o amicus curiae, as audiências públicas, as comissões parlamentares, os conselhos municipais, os Portais de Transparência e o e-Sic (apenas em espaços transparentes é possível a legitimação material da participação, por isso da inclusão dos dois últimos mecanismos). A intepretação democrática e plural proposta pelo autor deve ocorrer já quando da elaboração da lei. É o Poder Legislativo o primeiro a garantir os direitos fundamentais, sendo que ao Poder Executivo cabe a garantia material dos mesmos, através da prestação de ações e serviços. O Poder Judiciário, nessa visão, é o último a concretizar os direitos fundamentais.

Em última análise: a atuação e relação entre os Poderes Estatais no âmbito do Estado Democrático de Direito, frente à atualização e releitura da teoria proposta por Häberle, acarreta aos mesmos o dever de proporcionar espaços democráticos de participação social. Nessa dimensão, ao dever de proteção estatal dos direitos fundamentais e do seu procedimento é agregada a concepção de que esse procedimento deve ser público, aberto, plural e transparente, não podendo a sociedade atuar como mera destinatária dos direitos. Para tanto, a pluralidade e a abertura da interpretação devem ser tomadas como princípio do Direito, numa perspectiva legitimadora, identificada com a noção de res 
publica, que pressupõe, também, uma mudança acerca da forma de atuação dos Poderes Estatais e de seus deveres na efetivação dos direitos fundamentais.

\section{REFERÊNCIAS}

BRASIL. Supremo Tribunal Federal. Ação Direta de Inconstitucionalidade 2.469. Relator: Ministro Carlos Velloso. Brasília, DF, 26 de fevereiro de 2003. Disponível em: <http://www.stf.jus.br>. Acesso em: 04 mar. 2019.

BRASIL. Supremo Tribunal Federal. Ação Direta de Inconstitucionalidade 3.998. Relator: Ministro Gilmar Mendes. Brasília, DF, 31 de março de 2008. Disponível em: < http://www.stf.jus.br>. Acesso em: 04 mar. 2019.

HÄBERLE, Peter. Demokratische Verfassungstheorie im Lichte des Möglichkeitsdenkens (1977) mit Nachtrag (1978). In: Verfassung als öffentlicher Proze $\beta$ : Materialen zu einer Vefassungstheorie der offenen Gesellschaft. Berlin: Duncker \& Humblot, 1978a, p. 17-58.

. Demokratische Verfassungstheorie im Lichte des Möglichkeitsdenkens. In: Die Verfassung des Pluralismus: Studien zur Verfassungstheorie der offenen Gesellschaft. Königstein/Ts.: Athenäum, 1980a, p. 1-44.

. Die Grundrechte im demokratischen Staat (1974) mit Nachtrag (1978). In: Verfassung als öffentlicher Prozeß: Materialen zu einer Vefassungstheorie der offenen Gesellschaft. Berlin: Duncker \& Humblot, 1978e, p. 579-588.

Die offene Gesellschaft der Verfassungsinterpreten. In: Die Verfassung des Pluralismus: Studien zur Verfassungstheorie der offenen Gesellschaft. Königstein/Ts.: Athenäum, 1980c, p. 179-205.

Die offene Gesellschaft der Verfassungsinterpreten (1975) mit Nachtrag (1978). In: Verfassung als öffentlicher Prozeß: Materialen zu einer Vefassungstheorie der offenen Gesellschaft. Berlin: Duncker \& Humblot, 1978d, p. 155-181.

Hermenêutica constitucional. A sociedade aberta dos intérpretes da Constituição: contribuição para a interpretação pluralista e "procedimental" da Constituição. Tradução de Gilmar Ferreira Mendes. Porto Alegre: Sergio Antonio Fabris, 1997.

Libertad, igualdad, fraternidade. 1789 como historia, actualidad y futuro del Estado Constitucional. Madrid: MinimaTrotta, 1998a.

Pluralismo y Constitución: estudios de teoría constitucional de la sociedad abierta. Traducción de Emilio Mikunda-Franco. Madrid: Franco, $2002 a$. 
. Verfassungslehre als Kuturwissenschaft. 2. Auflage. Berlin: Duncker \& Humblot, 1998b.

. Teoría de la Constitución como ciencia de la cultura. Traducción de Emilio Mikunda. Madrid: Tecnos, 2002b.

Verfassungsinterpretation als öffentlicherProze $\beta$-ein Pluralismuskonzept (Freiburger Vortrag 1978), Originalbeitrag. In: Verfassung als öffentlicher Prozeß: Materialen zu einer Vefassungstheorie der offenen Gesellschaft. Berlin: Duncker \& Humblot, 1978c, p. 121-154.

.VerfassungsinterpretationalsöffentlicherProze $\beta$-einPluralismuskonzept. In: Die Verfassung des Pluralismus: Studien zur Verfassungstheorie der offenen Gesellschaft. Königstein/Ts.: Athenäum, 1980b, p. 45-78.

Zeit und Verfassung (1974) mit Nachtrag (1978). In: Verfassung als öffentlicher Prozeß: Materialen zu einer Vefassungstheorie der offenen Gesellschaft. Berlin: Duncker \& Humblot, 1978b, p. 59-92.

LEAL, Mônia Clarissa Hennig. Jurisdição constitucional aberta: reflexões sobre a legitimidade e os limites da jurisdição constitucional na ordem democrática - uma abordagem a partir das teorias constitucionais alemã e norte-americana. Rio de Janeiro: Lumen Juris, 2007.

: MAAS, Rosana Helena. O amicus curiae e o Supremo Tribunal Federal: fundamentos teóricos e análise crítica. Curitiba: Multideia, 2014.

MORLOK, Martin. Peter Häberle zum 70. Gubutstag. In: Archiv des öffentlichen Rechts (AöR), Band 129, Heft4. Tübingen: Mohr Siebeck, 2004, p. 327-229.

SEGADO, Francisco Fernández. Peter Häberle: la gigantesca construcción constitucional de un humanista europeo. In: HÄBERLE, Peter.La garantía del contenido esencial de los derechos fundamentales. Traducción española de Joaquín Brage Camazano. Madrid: Dykinson, 2003.

Recebido em: 15/04/2019.

Aprovado em: 02/07/2019. 